\title{
FATIGUE ANALYSIS OF A SHIP DECK
}

\author{
Article DOI: $\underline{\text { https://doi.org/10.35219/mtd.2018.3.02 }}$ \\ Roberto IVAȘCU
}

\author{
Department of Mechanical Engineering, University "Dunarea de Jos" of Galati, Romania \\ e-mail: roberto.ivascu@gmail.com
}

\begin{abstract}
The predicted lifespan of the ship deck can be confirmed by navigational exploitation, structural imperfections and geometry are sources of excitation in the vertical and longitudinal direction and have a decisive influence on the structure's vibration levels and implicitly on the evolution over time as a random signal of specific deformations and stresses respectively.

For the static calculation, the maximum stresses $\sigma$ were obtained from $536.57 \mathrm{MPa}, 500.15$ $\mathrm{MPa}$ and $481.92 \mathrm{MPa}$ for the analyzed cases: with right angle, connection radius $R=0.5 \mathrm{~m}$ and $R=1 \mathrm{~m}$. The recommended construction method is definitely the one in which the connection radius $R=1 \mathrm{~m}$.

For the fatigue calculation, a wear factor of $0.6118,0.5368$ and 0.5170 , respectively, was obtained because it was considered the worst case where the cuts in the ship deck do not have a stiffening bracket that directly affects the stress, displacement and wear factor. Stresses in the rest of the deck are below the critical limit. Due to the studied case, a life expectancy of about 1.92 years, 2.20 years and 2.28 years is estimated, after which cracks can occur in the area of cuts. .
\end{abstract}

Keywords: deck, hatchway, stress, fatigue, wear factor

\section{DECK CONSTRUCTION}

The objective of this work is to analyze fatigue for an offshore shipbuilding deck, an example of this deck being given in Fig. 1 .

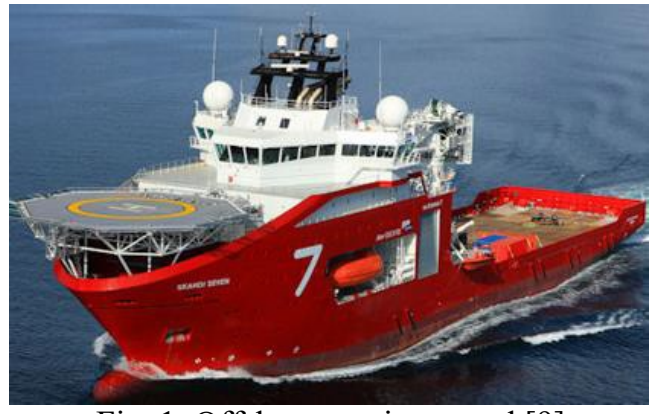

Fig. 1. Offshore service vessel [9]

The points of interest are the two hatches in the ship's deck, where the hatch brackets have been removed to study the worst case. This is where fatigue cracks appear.

The deck's structure consists of longitudinal and transversal beams, "T" profile and a flat profile. Deck's structure is made of AH32 steel with properties: yield strength of $300 \mathrm{MPa}$ and tensile strength of $400 \mathrm{MPa}$.
Ship characteristics are: length $-133.424 \mathrm{~m}$, width $-27 \mathrm{~m}$, block coefficient (C B) -0.85 , transverse strength modulus of the deck W -12.5 $\mathrm{m}^{\wedge} 3$. The deck is divided in 4 zones, depending on the thickness (Table 1).

Table 1

\begin{tabular}{|c|c|}
\hline Zone & Deck thickness [mm] \\
\hline 1 & 20 \\
\hline 2 & 15 \\
\hline 3 & 14 \\
\hline 4 & 12 \\
\hline
\end{tabular}

The areas most prone to fatigue cracks are in zones 1 and 3 , due to the hatchways. The deck structure consists of longitudinal and transverse beams of "T" profiles and flat profiles, their dimensions varying according to the zone. The longitudinal beams consist of 36 flat profile beams, and one " $\mathrm{T}$ " profile, positioned in the center. The flat profile beams are positioned at $0.7 \mathrm{~m}$ of each other.

The dimensions of the longitudinal beams, depending on the zones, are presented in Table 2 and Fig. 2. Transverse beams consist of " $T$ " profile, dimensions differ depending of the zone they are located in. The dimensions are presented in Table 3. 
The hatchways are stress concentrators and the analysis will be done for 3 cases of the hatchways construction.

Tabel 2

\begin{tabular}{|c|c|c|c|}
\hline \multirow{2}{*}{$\begin{array}{c}\text { Zo- } \\
\text { ne }\end{array}$} & \multicolumn{3}{|c|}{ Dimensions [mm] } \\
\cline { 2 - 4 } & $\begin{array}{c}\text { Flat } \\
\text { profile }\end{array}$ & "T" Profile & $\begin{array}{c}\text { "T" profile } \\
\text { dimensions, [mm] }\end{array}$ \\
\hline 1 & $240 \times 12$ & W1800x30 & W 800x15 \\
& & F 1000x40 & F 300x25 \\
\hline 2 & $240 \times 11$ & W1800x30 & W 800x25 \\
& & F 1000x40 & F 450x45 \\
\hline 3 & $240 \times 11$ & W1800x25 & W 800x30 \\
& & F 500x40 & F 500x30 \\
\hline 4 & $240 \times 10$ & W 1800x25 & W 800x10 \\
& & F 500x40 & F 125x10 \\
\hline
\end{tabular}

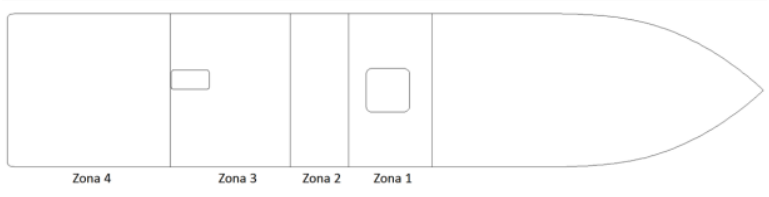

Fig. 2. Diving of the deck in zones [10]

Table 3

\begin{tabular}{|c|c|}
\hline Zone & "T" Profile dimensions [mm] \\
\hline 1 & $\begin{array}{l}\text { W } 800 \times 15 \\
\text { F } 300 \times 25\end{array}$ \\
\hline 2 & $\begin{array}{l}\text { W } 800 \times 25 \\
\text { F } 450 \times 45\end{array}$ \\
\hline 3 & $\begin{array}{l}\text { W } 800 \times 30 \\
\text { F } 500 \times 30\end{array}$ \\
\hline 4 & $\begin{array}{l}\text { W } 800 \times 10 \\
\text { F } 125 \times 10\end{array}$ \\
\hline
\end{tabular}

\section{STRESSES}

Fatigue analysis is performed in the COSMOS/M finite element analysis software [11] in the worst case scenario and the stress limit is needed to be known [1-4].

The stress is calculated with the relation (1):

$$
\sigma=\frac{M}{W}
$$

In the case of ships, the fatigue occurs due to two distinct moments of hogging and sagging. These moments are calculated according to classification societies in the field, the moments sign convention being given in Fig. 3. In Fig. 4, hogging and sagging moments are exemplified [10].

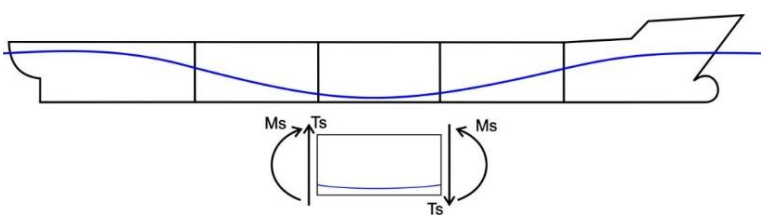

Fig. 3. Moments sign convention

Since the cracks are located on the deck, the author can consider the main loading, the bending load of the beam-ship, resulting in the moment of: sagging that occurs when the ship is out of the wave. Similarly, the hogging moments occur when the ship is on the wave crest.

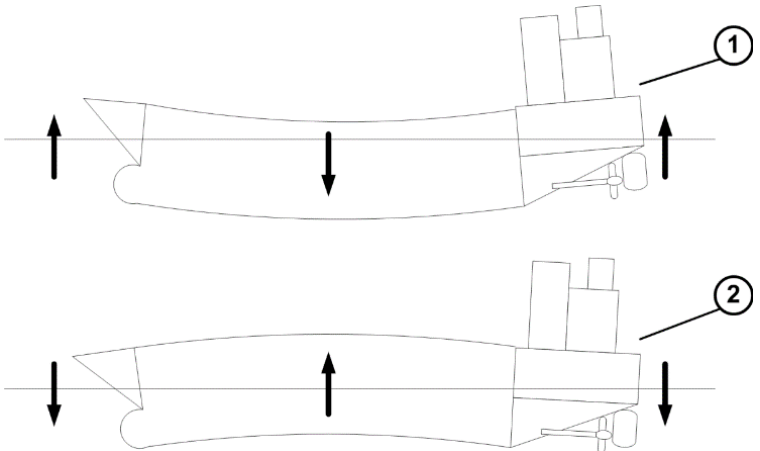

Fig. 4. Sagging (1) and Hogging (2) [10]

According to the Bureau Veritas Register, relation (2) presents the moments of bending of hogging and sagging, in calm water [5]:

$$
\begin{aligned}
& M_{S W M, H}=175 \cdot n_{1} \cdot C \cdot L^{2}\left(C_{2}+0.7\right) 10^{-3}-M_{W V, H} \\
& M_{S W M, S}=175 \cdot n_{1} \cdot C \cdot L^{2}\left(C_{2}+0.7\right) 10^{-3}-M_{W V, S}
\end{aligned}
$$

$M_{S W M, H}$ and $M_{S W M, S}$ are bending moments of hogging and sagging of the waves.

$$
\begin{aligned}
& M_{S W M, H}=190 \cdot F_{M} \cdot n \cdot C \cdot L^{2} \cdot B \cdot C_{B} \cdot 10^{-3} \\
& M_{S W M, S}=-110 \cdot F_{M} \cdot n \cdot C \cdot L^{2} \cdot B \cdot C_{B} \cdot 10^{-3} \\
& C_{B}=0.85-\text { block coefficient; } \\
& n_{1}, n=1-\text { coefficient of navigation in }
\end{aligned}
$$

unrestricted area;

$\mathrm{B}=27 \mathrm{~m}-$ ship width;

$\mathrm{L}=133.424 \mathrm{~m}-$ ship length;

$F_{M}=1$ - distribution factor;

$\mathrm{C}=7.98$ - wave parameter calculated with the relation (4) [5]:

$$
\begin{gathered}
C=10.75-\left(\frac{300-L}{100}\right)^{1.5} \\
M_{S W M, H}=-580882.45 \mathrm{kN} \cdot \mathrm{m} \\
M_{S W M, S}=615400.88 \mathrm{kN} \cdot \mathrm{m} .
\end{gathered}
$$

To calculate the maximum hogging and sagging stresses, the strength modulus of the deck is needed, $\mathrm{W}=12.5 \mathrm{~m}^{3}$, thus, it results $\sigma_{H}=-46.47 \mathrm{MPa}$ and $\sigma_{s}=49.23 \mathrm{MPa}$.

\section{MODELING}

With the COSMOS/M finite element analysis software, the author modeled the deck consisting of the 4 zones. The modeled deck has two hatchways, a main one positioned on the symmetry axis in zone $17672 \mathrm{~mm} \times 7676 \mathrm{~mm}$ and the secondary located in zone $33380 \mathrm{~mm}$ x $6680 \mathrm{~mm}$.

The model is made in accordance with the details of the technical drawing [12], except for the rounded corners of the hatches that have been made at a $90^{\circ}$ angle to make a comparison and to demonstrate their importance in reducing stresses. 
Deck dimensions are: length $-75 \mathrm{~m}$, width -27 $\mathrm{m}$, deck thickness: zone $1-20 \mathrm{~mm}$, zone $2-15 \mathrm{~mm}$, zone $3-15 \mathrm{~mm}$, zone $4-12 \mathrm{~mm}$.

The deck will be modeled with the 4 thicknesses and the beams that represent the structure of the deck. The mesh will consist of SHELL 4T type elements. The average size of an element is $500 \mathrm{~mm}$ and all are quadrilateral.

The longitudinal and transverse beams, which are flat and with "T" profiles, are built. Both the flat and the "T" profiles are modeled with SHELL4T elements, and the "T" profile foot is modeled with BEAM3D elements to which the author has computed and introduced the inertia and I_y and I_z moments. The "T" profile plate is modeled with BEAM3D elements, it is not visible in the model. This approach was preferred because of the different dimensions in deck areas, the beams would not have worked together from one area to another. After modeling and meshing the deck (Figures 5-7), it is noticed that the system contains approximately 120000 quadrilateral elements.

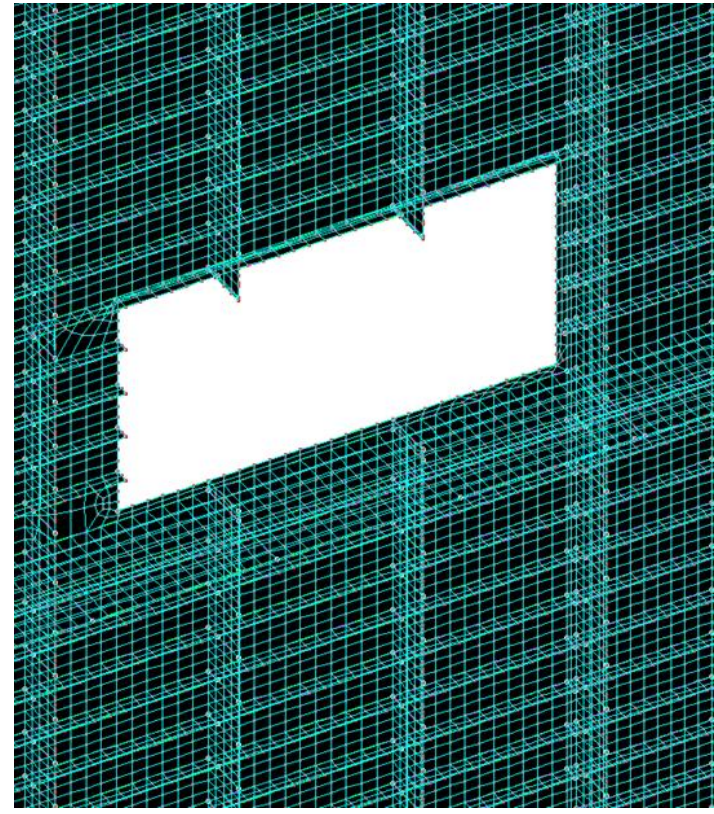

Fig. 6. Meshing of the secondary hatch

\section{STATIC ANALYSIS}

The model is loaded with 2 linear pressures: $\sigma_{H}=-46.47 \mathrm{MPa}$ and $\sigma_{s}=49.23 \mathrm{MPa}$ on the sectioned part of the deck.

On the outline of the deck, the following constraints are introduced:

- the stern part of the deck is fixed,

- the deck sides have 5 degrees of freedom blocked with the exception of the $\mathrm{X}$ axis translation in order to permit the distribution of the load,

- the sectioned part of the deck near the main hatchet is free because that is the zone where the load is applied.

The analysis is done in three cases (design solutions) of the main hatch:

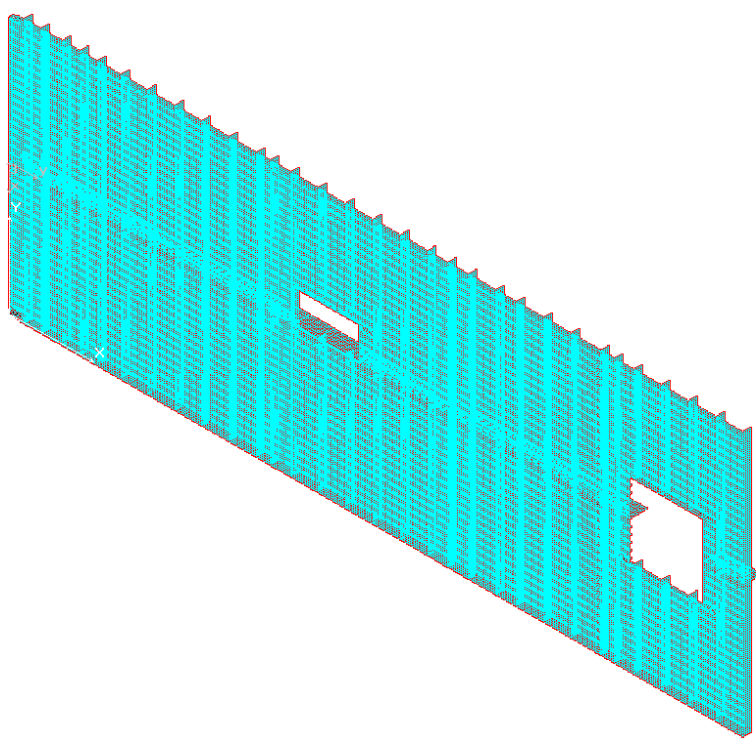

Fig. 5. Meshing of the deck

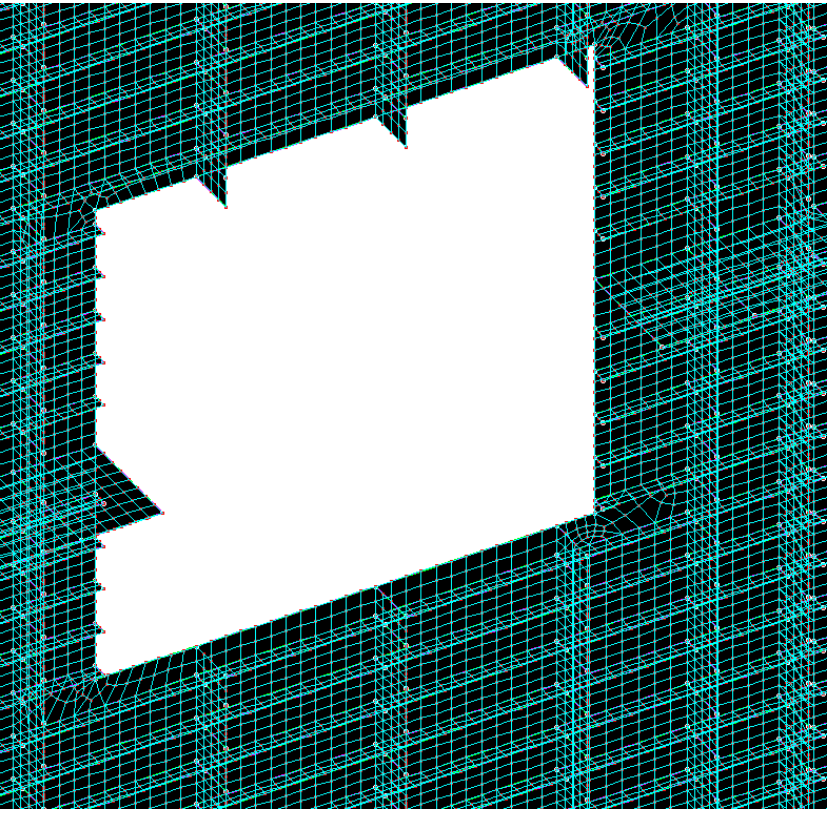

Fig. 7. Meshing of the main hatch

- without radius (design angle $90^{\circ}$ ) (Figures 8-11, including main stresses $\sigma_{1}$ and $\sigma_{2}$ and corresponding displacements),

- corner radius $\mathrm{R}=0.5 \mathrm{~m}$ (Figures $12-15$, including main stresses $\sigma_{1}$ and $\sigma_{2}$ and corresponding displacements),

- corner radius $\mathrm{R}=1 \mathrm{~m}$ (Figures 16-19, including main stresses $\sigma_{1}$ and $\sigma_{2}$ and corresponding displacements).

The second hatch has following cases:

- without radius (design angle $90^{\circ}$ ),

- corner radius $r=0.1 \mathrm{~m}$.

This approach has been chosen because it is noted that the stress in the secondary hatchway is inferior to the main one. Stresses and displacements are all shown in Table 4. 

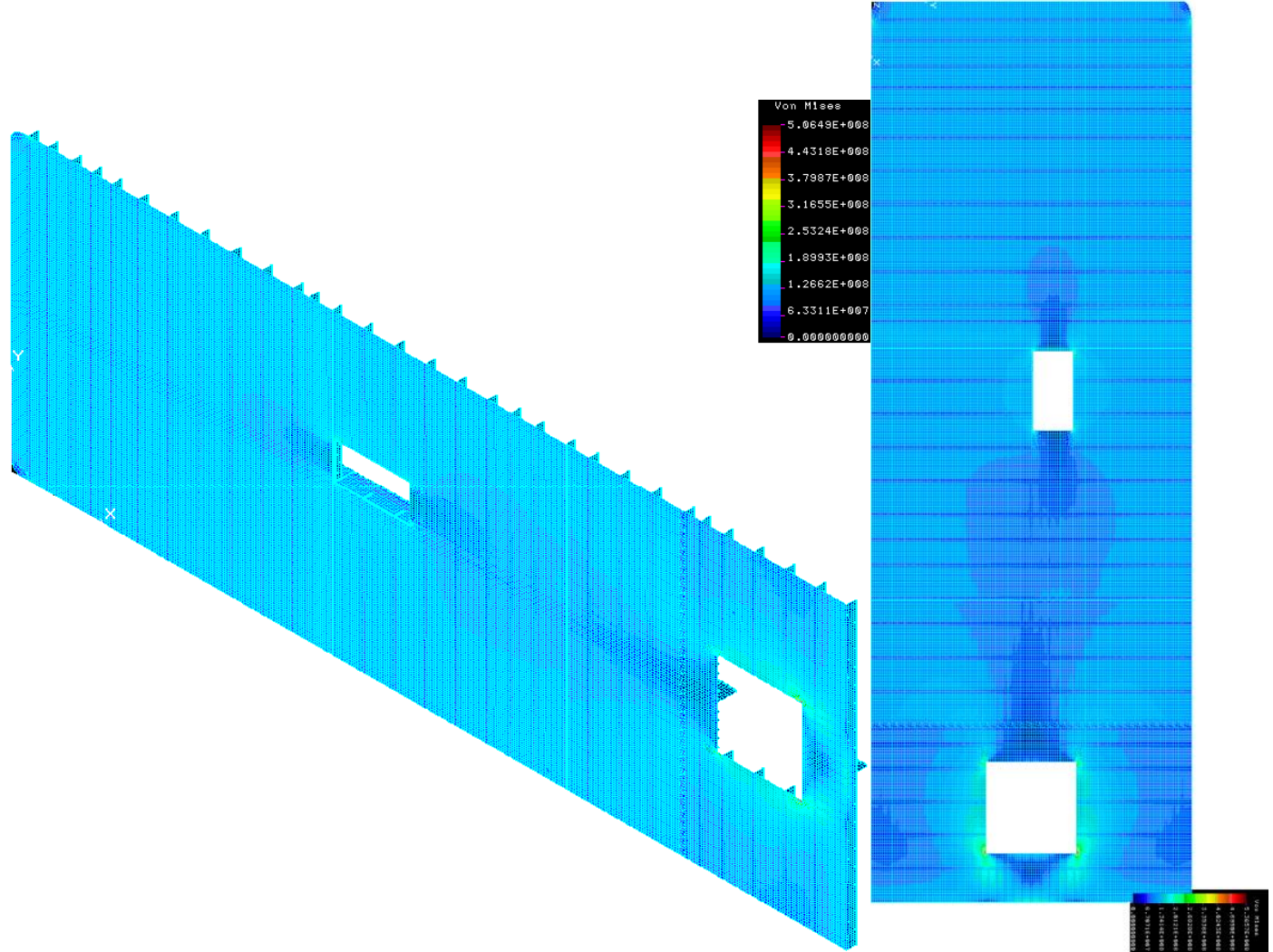

Fig. 8. Stress $\sigma_{1}$ for an angle of $90^{\circ}$

Fig. 9. Stress $\sigma_{2}$ for an angle of $90^{\circ}$

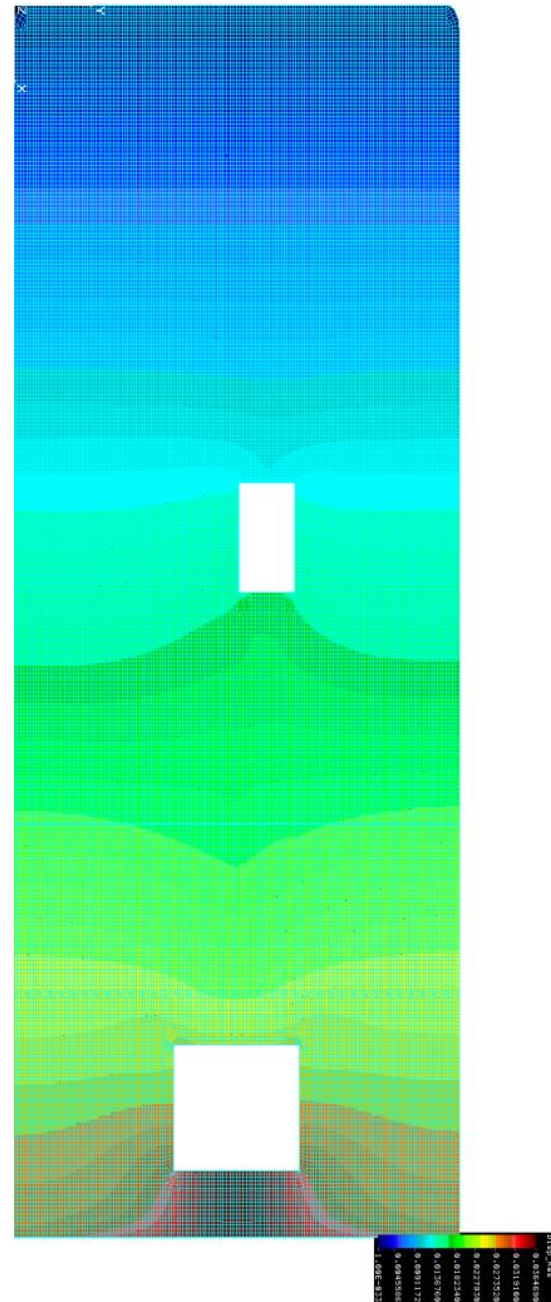

Fig. 10. Displacement $\Delta_{1}$ for an angle of $90^{\circ}$

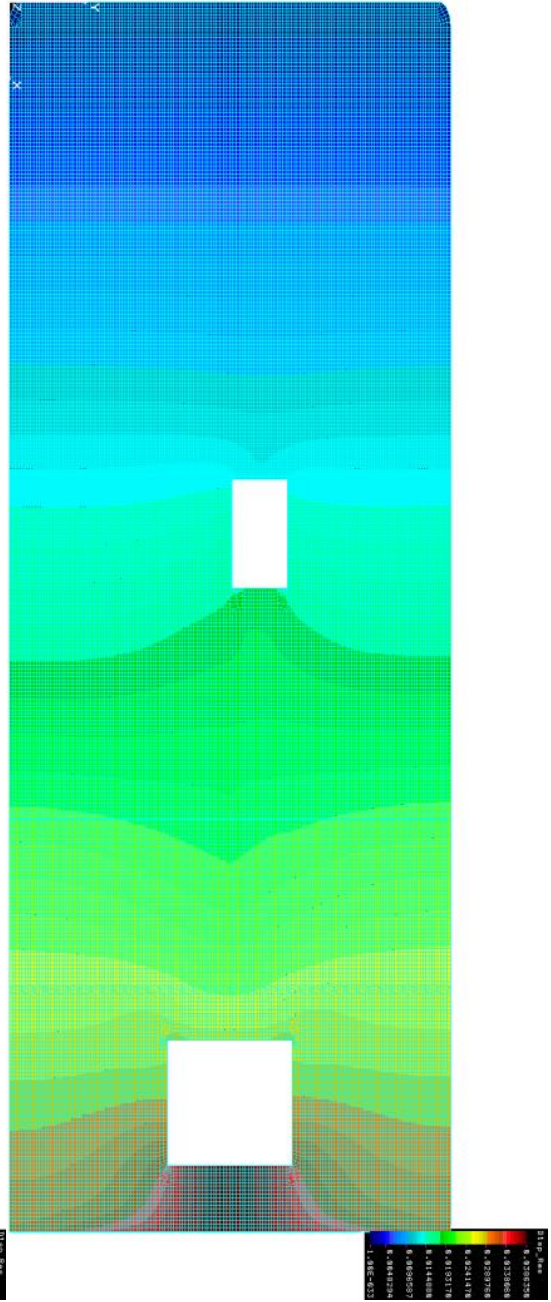

Fig. 11. Displacement $\Delta_{2}$ for an angle of $90^{\circ}$ 


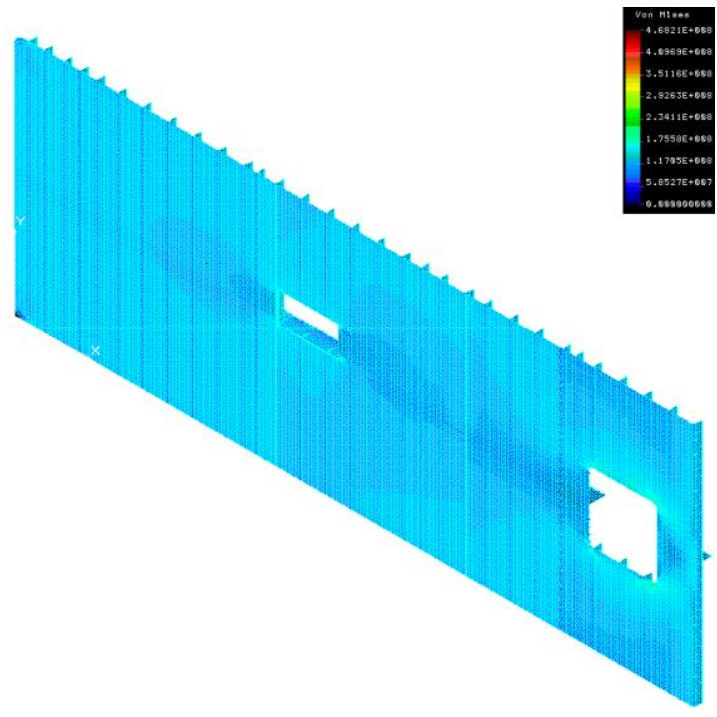

Fig. 12. Stress $\sigma_{1}$ for $\mathrm{R}=0.5 \mathrm{~m}, \mathrm{r}=0.1 \mathrm{~m}$

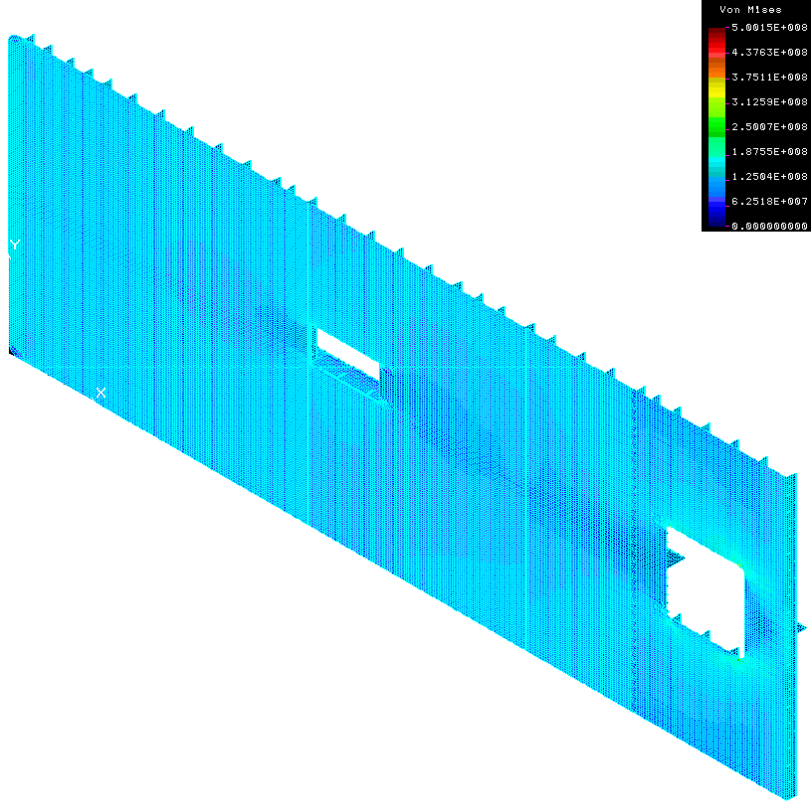

Fig. 13. Stress $\sigma_{2}$ for $\mathrm{R}=0.5 \mathrm{~m}, \mathrm{r}=0.1 \mathrm{~m}$

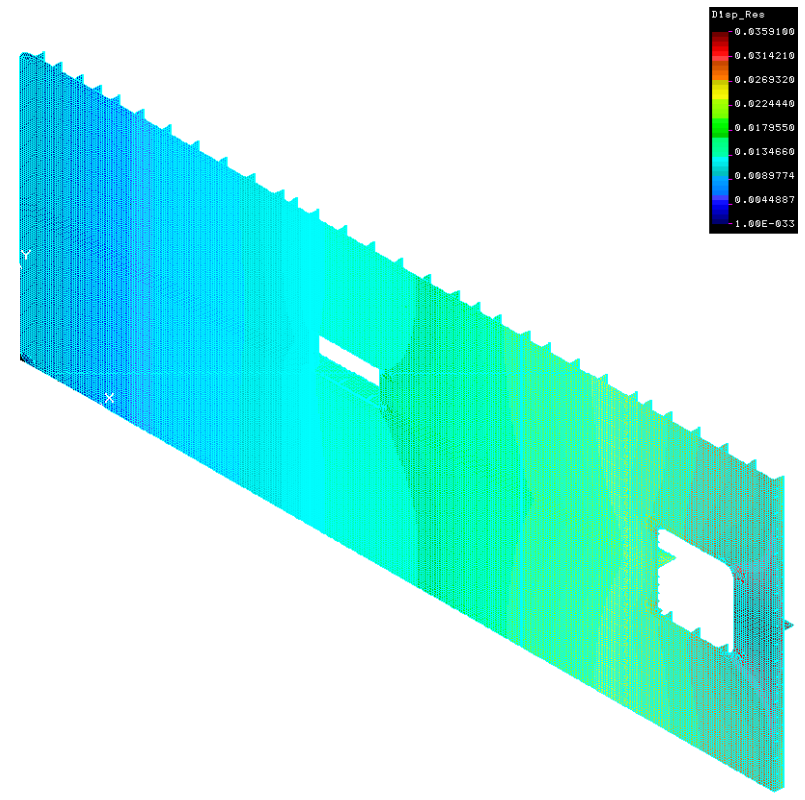

Fig. 14. Displacement $\Delta_{l}$ for $\mathrm{R}=0.5 \mathrm{~m}, \mathrm{r}=0.1 \mathrm{~m}$ 


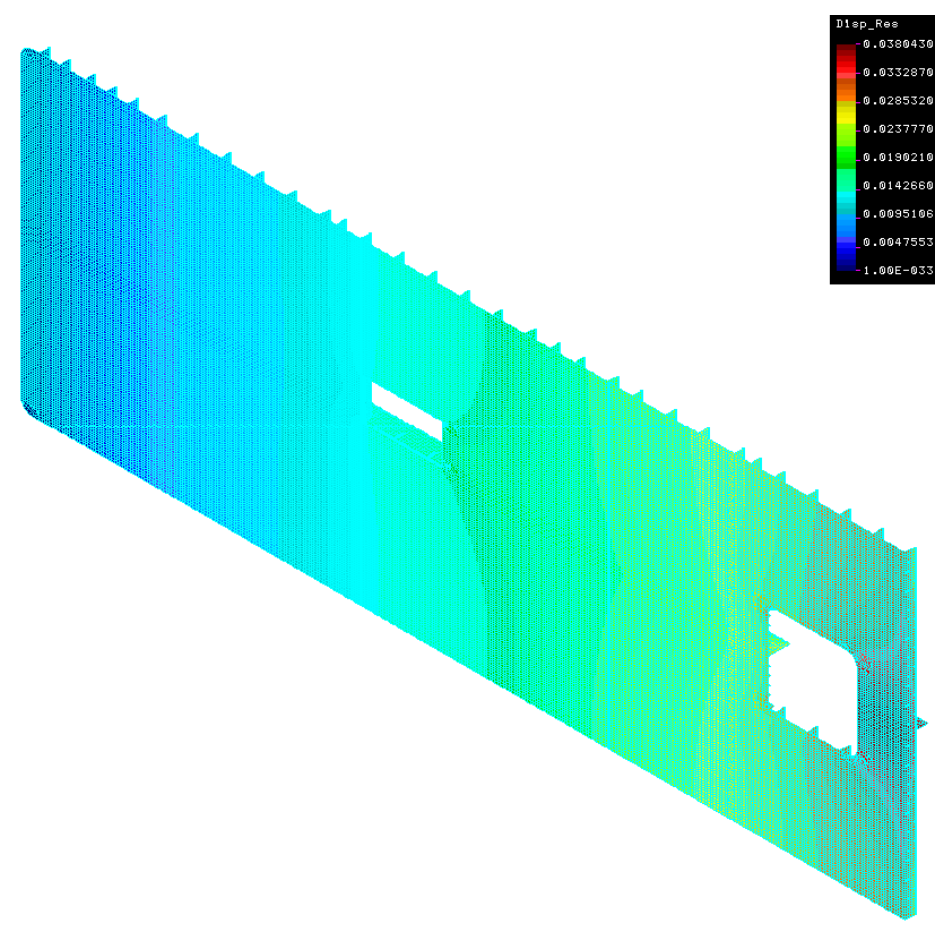

Fig. 15. Displacement $\Delta_{2}$ for $\mathrm{R}=0.5 \mathrm{~m}, \mathrm{r}=0.1 \mathrm{~m}$
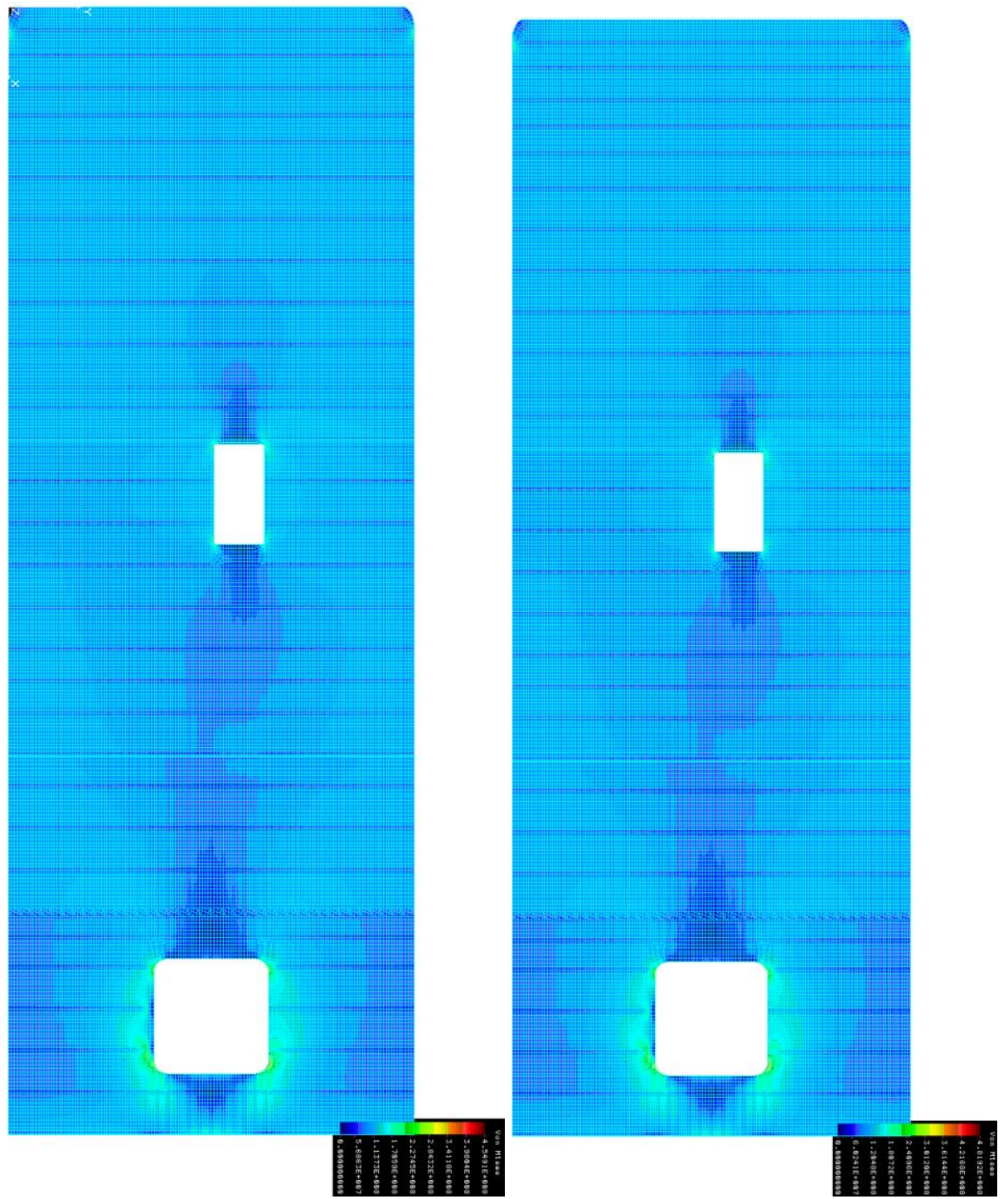

Fig. 16. Stress $\sigma_{l}$ for $\mathrm{R}=1 \mathrm{~m}, \mathrm{r}=0.1 \mathrm{~m}$

Fig. 17. Stress $\sigma_{2}$ for $\mathrm{R}=1 \mathrm{~m}, \mathrm{r}=0.1 \mathrm{~m}$ 


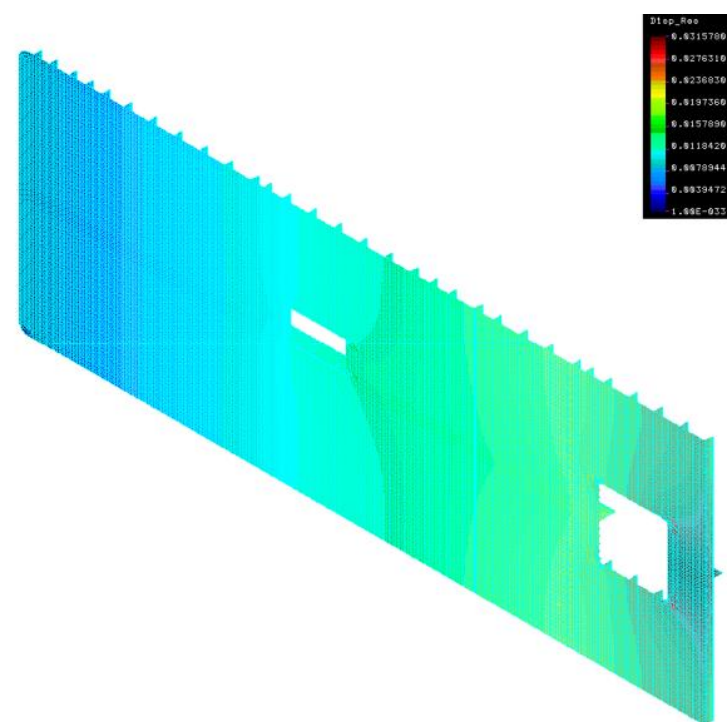

Fig. 18. Displacement $\Delta_{l}$ for $\mathrm{R}=1 \mathrm{~m}, \mathrm{r}=0.1 \mathrm{~m}$

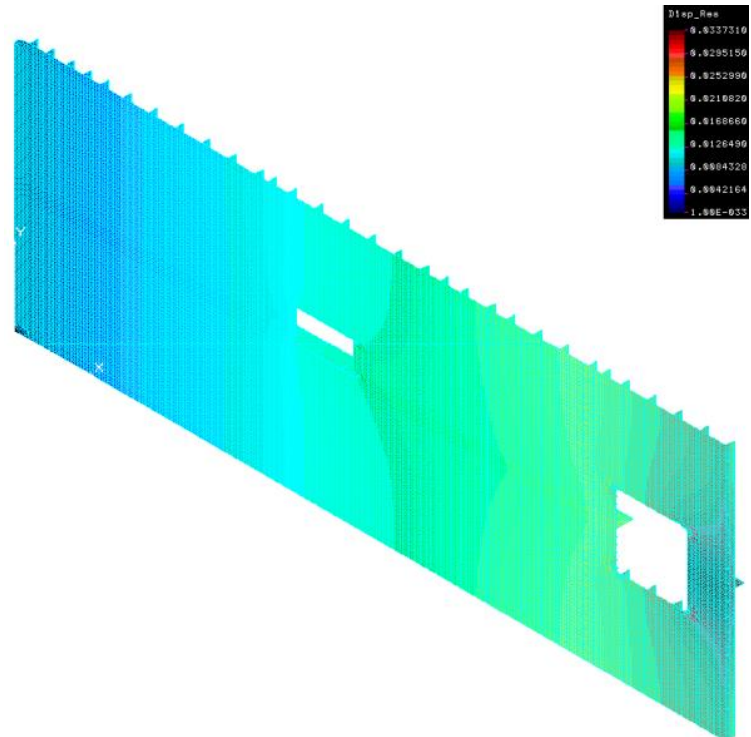

Fig. 19. Displacement $\Delta_{2}$ for $\mathrm{R}=1 \mathrm{~m}, \mathrm{r}=0.1 \mathrm{~m}$

Table 4

\begin{tabular}{|c|c|c|c|c|}
\hline $\mathrm{w}$ & $\sigma_{1}[\mathrm{~Pa}]$ & $\sigma_{2}[\mathrm{~Pa}]$ & $\Delta_{l}[\mathrm{~m}]$ & $\Delta_{2}[\mathrm{~m}]$ \\
\hline $90^{\circ}$ & $5.0649 \mathrm{E}+8$ & $5.3657 \mathrm{E}+8$ & 0.036469 & 0.038635 \\
\hline $\mathrm{R}=0.5 \mathrm{~m}$ & $4.6821 \mathrm{E}+8$ & $5.0015 \mathrm{E}+8$ & 0.035910 & 0.038043 \\
\hline $\mathrm{R}=1 \mathrm{~m}$ & $4.5491 \mathrm{E}+8$ & $4.8192 \mathrm{E}+8$ & 0.031578 & 0.033731 \\
\hline
\end{tabular}

In time, the evolution of main stresses and displacements are given in Figures 20 and 21.

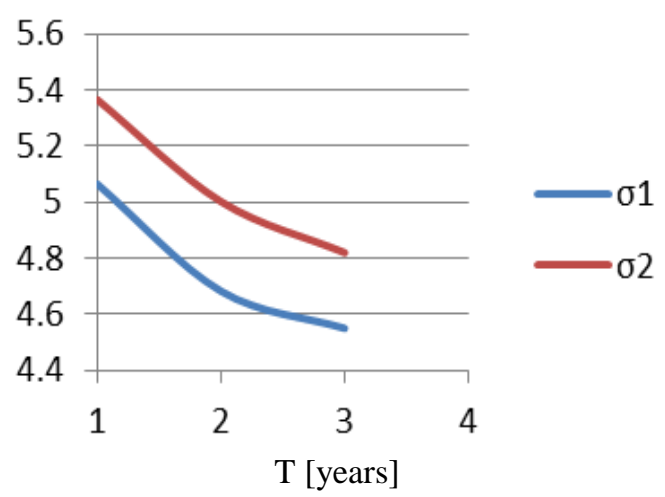

Fig. 20. Stresses $\sigma_{1}$ and $\sigma_{2}[\mathrm{x} \mathrm{E}+8 \mathrm{~Pa}]$, in time

\section{FATIGUE ANALYSIS}

To perform the fatigue analysis, it is necessary to determine the node where the stress is maximum, also called the hot spot.

With the results from the static analysis, the author identified the "hot spots" (Table 5) that will be entered into the COSMOS/M fatigue module.

Table 5

\begin{tabular}{|c|c|}
\hline Studied cases & Hot spots \\
\hline $90^{\circ}$ & 11797 \\
\hline $\mathrm{R}=0.5 \mathrm{~m}$ & 147645 \\
\hline $\mathrm{R}=1 \mathrm{~m}$ & 147646 \\
\hline
\end{tabular}

To use the fatigue module in COSMOS/M software, the number of events was defined (Table 6 ), each event having a number of cycles, for which

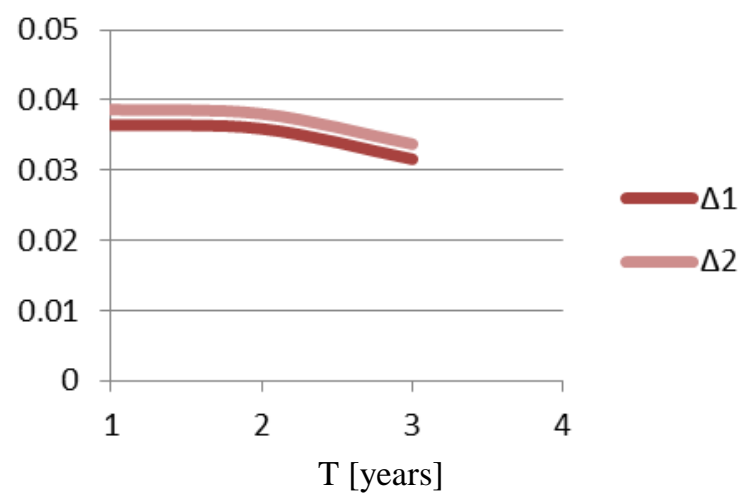

Fig. 21. The variation of displacements $\Delta_{1}$ and $\Delta_{2}[\mathrm{~m}]$

fatigue analysis is performed. In this case, two events were involved, with a number of cycles equal to 15000 and 7000, respectively. The load corresponding to each event (Table 7, Fig. 22) is defined, the cases being those previously used for the static analysis: $\sigma_{H}=-46.47 \mathrm{MPa}$ and $\sigma_{s}=49.23 \mathrm{MPa}$.

It was inserted the curve for the steel from which the deck is made (Fig. 26), steel AH32, having the properties: yield strength $300 \mathrm{MPa}$ and tensile strength $400 \mathrm{MPa}$.

Table 6

\begin{tabular}{|c|c|}
\hline Event number & Cycles \\
\hline 1 & 15000 \\
\hline 2 & 7000 \\
\hline
\end{tabular}


Table 7

\begin{tabular}{|c|c|c|}
\hline Reference point & Event & Loading case \\
\hline 1 & 1 & 0 \\
\hline 2 & 1 & 1 \\
\hline 3 & 1 & 1 \\
\hline 4 & 2 & 0 \\
\hline 5 & 2 & 2 \\
\hline 6 & 2 & 2 \\
\hline 7 & 2 & 0 \\
\hline
\end{tabular}

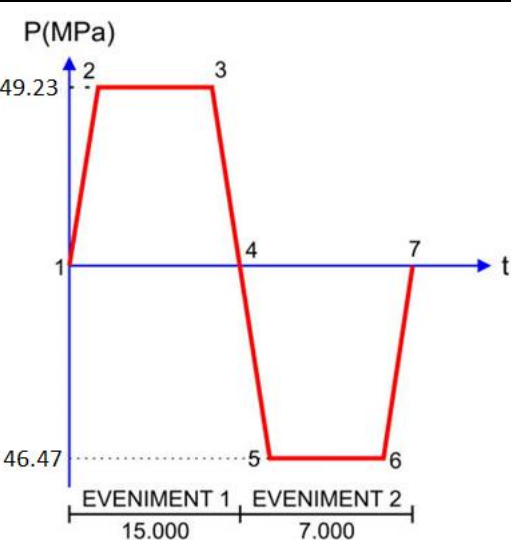

Fig. 22. Loading

Estimated lifetime can be determined by reversing the resulting cumulative wear in Table 8 , the results being given in Table 9 [6-10]. Assuming that $85 \%$ of the lifetime of a ship operates at a lifetime, the lifetime is calculated by:

$$
T=\frac{1}{0.85 \cdot D}
$$

$D$ - wear factor; $T$ - lifetime.

Table 8

\begin{tabular}{|c|c|}
\hline Studied cases & $\begin{array}{c}\text { Wear factor } \\
\text { (Fig. 27) }\end{array}$ \\
\hline $90^{\circ}$ angle (Fig. 23) & 0.611802 \\
\hline $\mathrm{R}=0.5 \mathrm{~m}$ (Fig. 24) & 0.536831 \\
\hline $\mathrm{R}=1 \mathrm{~m}$ (Fig.25) & 0.517005 \\
\hline
\end{tabular}

Table 9

\begin{tabular}{|c|c|}
\hline Studied case & $\begin{array}{c}\text { Lifetime [years] } \\
\text { (Fig. } 28 \text { ) }\end{array}$ \\
\hline $90^{\circ}$ angle & 1.92 \\
\hline $\mathrm{R}=0.5 \mathrm{~m}$ & 2.20 \\
\hline $\mathrm{R}=1 \mathrm{~m}$ & 2.28 \\
\hline
\end{tabular}

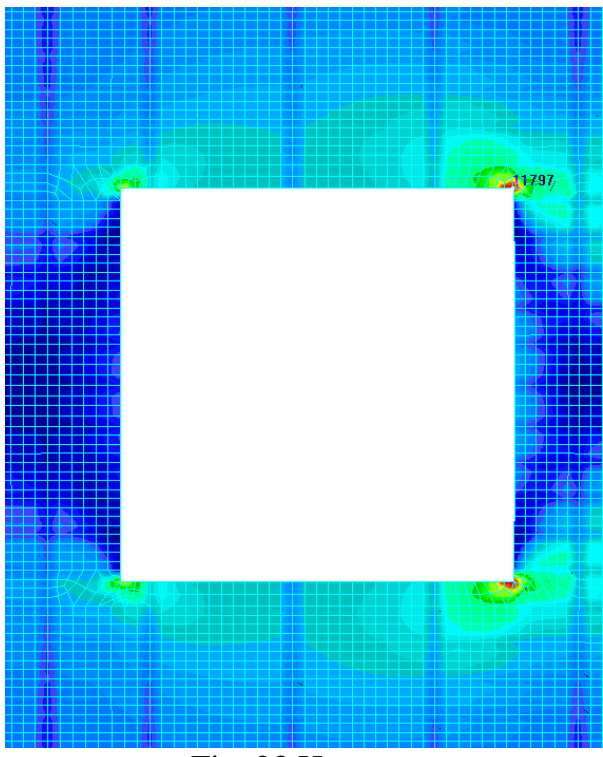

Fig. 23 Hot spot for an angle of $90^{\circ}$

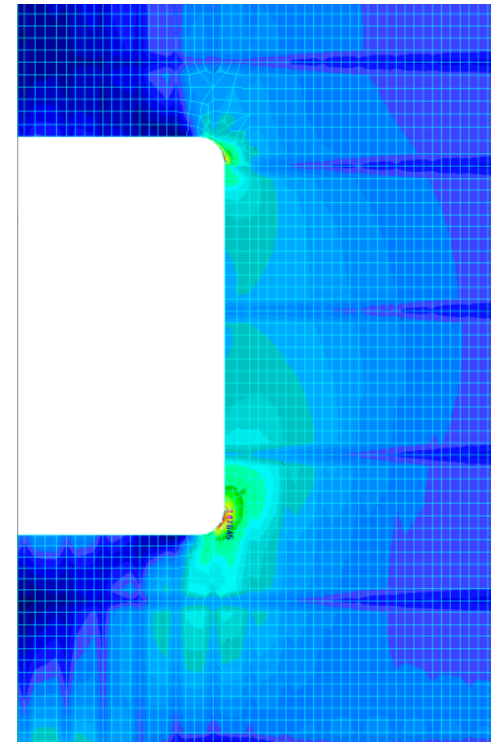

Fig. 24. Hot spot for corner radius $\mathrm{R}=0.5 \mathrm{~m}$

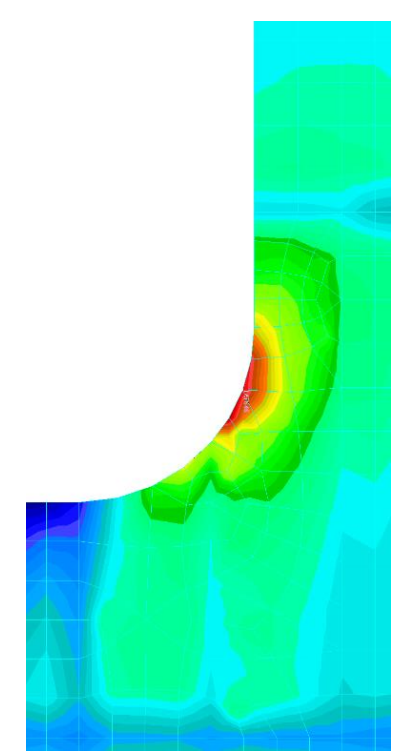

Fig. 25. Hot spot for corner radius $R=1 \mathrm{~m}$

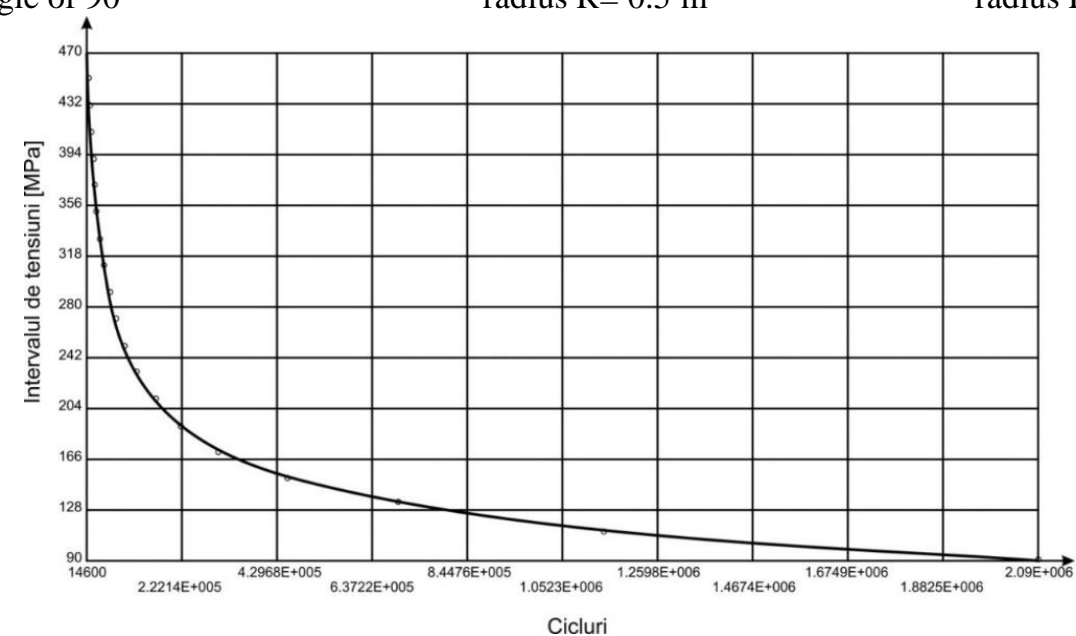

Fig. 26. S-N Curve [6] 


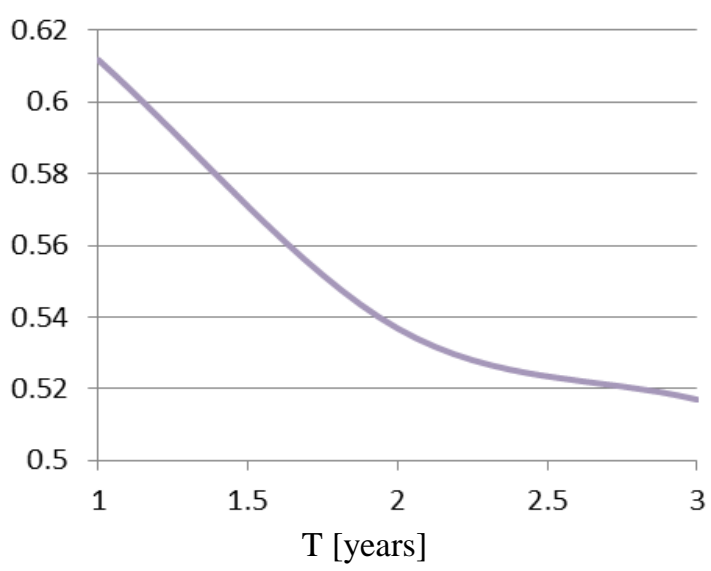

Fig. 27. Variation of the wear factor D

\section{CONCLUSIONS}

Static tests only provide the ability to locate the most requested areas to be investigated in a dynamic test during ship operation or fatigue on the stand. In the tests, the method of estimating fatigue resistance using the S-N fatigue diagrams allows only the appreciation of a grading within the limits imposed by the diagrams. The method of determining the length of life sets out in advance a forecast of the number of miles of sailing that has been traversed until the crack has occurred, allowing for the implementation of far more elaborate technological and constructive solutions and with certain chances of correcting the load bearing structure to improve resilience to random loads due to operating loads. Fatigue tests on specialized stands applied to the subassemblies, using experimentally established tests, are sometimes imperative for determining the technical solutions adopted.

In conclusion, in order to properly model and analyze a fatigue problem, sequences of variable stresses that can produce or not damage the structure through fatigue must be determined.

For fatigue modeling and analysis, studying the conditions of cracks and their evolution is clearer and more effective if associated with the concepts and means of investigation of tensile mechanics. In this way, it is possible to track the evolution of the cracks over time and to estimate the moment when they can endanger the integrity of the structure. This is justified by the fact that all real structures have faults and cracks.

The predicted lifespan of the ship's deck can be confirmed by navigational exploitation, structural imperfections and geometry are sources of excitation in the vertical and longitudinal direction and have a decisive influence on the structure vibration levels and, implicitly, on the evolution in time as a random signal of specific deformations and stresses, respectively.

Depending on the type of structure, the request staff offers varying degrees of damage on the same number of miles of navigation. Thus, lifetime differs spectacularly according to the degree of stress

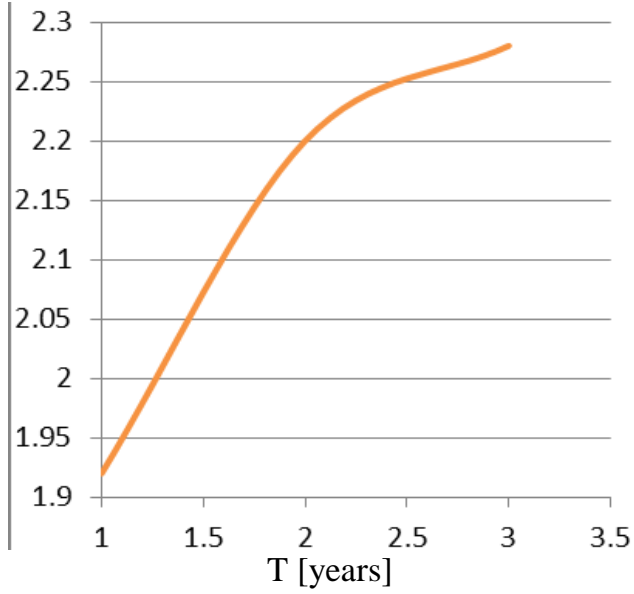

Fig. 28. Variation of the lifetime $\mathrm{T}$ [years]

expressed by the stress $\sigma$ and the degree of fullness of the wave requesting body in direct relationship with the ship.

For the static calculation the maximum stresses $\sigma$ were obtained from $536.57 \mathrm{MPa}, 500.15 \mathrm{MPa}$ and $481.92 \mathrm{MPa}$ for the analyzed cases: with right angle, with connection radia $\mathrm{R}=0.5 \mathrm{~m}$ and $\mathrm{R}=1 \mathrm{~m}$. The recommended construction method is definitely the one in which the connection radius $\mathrm{R}=1 \mathrm{~m}$.

For the fatigue calculation, a wear factor of $0.6118,0.5368$ and 0.5170 , respectively, was obtained because it was considered the worst case where the cuts in the ship deck do not have a stiffening bracket that directly affects the stress, displacement, and factor Wear. Note that stresses in the rest of the deck are below the critical limit. Due to the studied case, a life expectancy of about 1.92 years, 2.20 years and 2.28 years is estimated, after which cracks can occur in the area of cuts.

\section{REFERENCES}

1. Radeş M., Rezistența materialelor II, Editura Printech, Bucureşti, 2007

2. Buzdugan G., Rezistenţa materialelor, Editura Tehnica, Bucureşti, 1974

3. Mocanu F., Rezistența materialelor partea a II-a

4. Andreescu I., Mocanu Şt., Probleme de rezistenţa materialelor, Bucureşti, 2003

5. Bureau Veritas, Rules for the classification of steel ships, Part B - Hull and stability, 2011

6. DNV, Classification notes No. 30.7, Fatigue assesment of ship structures, 2014

7. International Ship Structures Congress, Fatigue strength assessment, 2003

8. DNV, DNV-RP-C203, Fatigue design of offshore steel structures, 2011

9. $* * *$ Offshore Ships Equipmenhttp://www.ttsgroup.com/PageFiles/1 292/offshoreSE.jpg

10. $* * *$ Hogging and sagging, https://en.wikipedia. org/wiki/Hogging_and_sagging

11. Soft analysis with finite elements: COSMOS/M

12. Autodesk AutoCAD 